\title{
Acne fulminans - medical emergency in the practice of the family doctor
}

\author{
Acneea fulminans - urgență medicală în practica medicului de familie \\ Ana Maria Alexandra STĂNESCU ${ }^{1}$, Ioana Veronica GRĂJDEANU ${ }^{1}$, Ana Maria GOANȚ̆², \\ Călin GIURCĂNEANU ${ }^{1}$ \\ ${ }^{1}$ Universitatea de Medicină şi Farmacie „Carol Davila“, Bucureşti, România \\ ${ }^{2}$ Facultatea de Medicină Veterinară, Bucureşti, România
}

\begin{abstract}
Acne is a common affection in the family doctor's office, usually treating light acne forms. It is very important to detect acne fulminans as soon as possible. This is a rare but very destructive form, with systemic implications, requiring immediate specialist treatment, usually requiring hospitalization.
\end{abstract}

Keywords: acne, acne fulminans, medical emergency, family doctor

\section{- REZUMAT}

Acneea este o afecțiune foarte des întâlnită în cabinetul medicului de familie, care de obicei tratează formele uşoare de acnee. Este foarte important de depistat cât mai repede acneea fulminans. Aceasta este o formă rară, însă foarte distructivă, cu implicații sistemice, care necesită tratament de specialitate imediat, necesitând de cele mai multe ori internarea bolnavului.

Cuvinte cheie: acnee, acnee fulminans, urgență medicală, medic de familie

\section{INTRODUCERE}

Abordarea acneei, atât de des întâlnită în practica medicală, în mod deosebit la adolescenți, este un subiect comun în rândul medicilor. Cu toate acestea, există și forme grave de acnee care necesită instituirea terapiei specifice de către medicul specialist.

Pacientul este afectat în principal din cauza aspectului, nu tocmai plăcut, ce poate duce la afectarea calității vieții. Gradul de afectare a calității vieții pacientului cu acnee este în general direct proporțional cu severitatea bolii.

De obicei, formele ușoare și cele moderate se vindecă fără complicații majore (pot rămâne cicatrici în unele cazuri). Trebuie să conștientizăm posibilitatea exacerbării formelor ușoare și complicațiile care pot surveni o dată cu formele severe de acnee.

Deși o afecțiune comună, acneea se încadrează în bolile inflamatorii ale foliculului pilos și rezultă dintr-o interacțiune complexă a diferiților factori patogeni.

Este o boală cronică caracterizată prin episoade de exacerbare și de remisie. Tratamentul este astăzi înțeles ca abordare pe termen lung (luni sau ani).

În literatura de specialitate sunt menționate numeroase forme și clasificări ale acneei, o parte din acestea sunt prezentate în Tabelul 1. 
TABELUL 1. Exemplificarea formelor de acnee

\begin{tabular}{|l|l|}
\hline Formă & Observații \\
\hline $\begin{array}{l}\text { Acneea } \\
\text { vulgară }\end{array}$ & $\begin{array}{l}\text { Cea mai frecventă formă de acnee. Apare } \\
\text { în perioada pubertății și se remite (de obi- } \\
\text { cei) după } 20 \text { ani. Este caracteristic excesul } \\
\text { de sebum și prezența comedoanelor închi- } \\
\text { se și/sau deschise, papule, pustule, noduli, } \\
\text { cicatrici. }\end{array}$ \\
\hline $\begin{array}{l}\text { Acneea } \\
\text { fulminans }\end{array}$ & $\begin{array}{l}\text { Formă severă de acnee. Predominant la se- } \\
\text { xul masculin. Debut exploziv cu leziuni de } \\
\text { dimensiuni mari. Sunt specifice leziunile ul- } \\
\text { cerative cu cruste hemoragice. Este însoțită } \\
\text { de simptomatologie sistemică specifică. }\end{array}$ \\
\hline $\begin{array}{l}\text { Acneea } \\
\text { conglobată }\end{array}$ & $\begin{array}{l}\text { Formă severă de acnee. Afectează fața, } \\
\text { trunchiul, fesele. Apar abcese care drenea- } \\
\text { ză prin sinusuri, dar și comedoane, papule, } \\
\text { pustule și noduli. }\end{array}$ \\
\hline $\begin{array}{l}\text { Acneea } \\
\text { medica- } \\
\text { mentoasă }\end{array}$ & $\begin{array}{l}\text { Apare în urma medicației cu corticosteroizi, } \\
\text { ioduri, bromuri, săruri de litiu, steroizi ana- } \\
\text { bolici etc. }\end{array}$ \\
\hline $\begin{array}{l}\text { Acneea la } \\
\text { nou-născut } \\
\text { și sugar }\end{array}$ & $\begin{array}{l}\text { Afectează în general copiii până la vârsta de } \\
\text { 3 ani. Frecvență mai redusă. Apar comedoa- } \\
\text { ne și papulo-pustule. Se remite spontan. }\end{array}$ \\
\hline
\end{tabular}

\section{ACNEEA FULMINANS}

Deși o formă rară de acnee, acneea fulminans este cea mai severă și distructivă formă, cu debut exploziv și simptomatologie sistemică $(1,2)$. Reprezintă o urgență medicală, cu intervenția medicului specialist (medicul dermatolog, iar în unele cazuri și medicul internist), de cele mai multe ori fiind necesară internarea.

Afectează cu precădere sexul masculin în perioada pubertății, având ca tipar preexistența acneei ușoare sau moderate timp de 1-2 ani înainte de debutul brusc al acneei fulminans.

\section{ETIOPATOGENIE}

Etiologia acneei fulminans este rămasă încă incertă; cu toate acestea, mai multe variante (teorii) au fost evidențiate în literatură. Un rol important în etiologia acneei fulminans este foarte probabil să fie jucat de infecție, de factori imunologici și/sau factori genetici.

În urma studiilor efectuate, s-au evidențiat următoarele teorii:

- Dezvoltarea acneei fulminans este asociată cu o reacție de hipersensibilitate mediată imunologic de tip III și/sau de tip IV la antigenii Propionibacterium acnes (3)

- Tratamentul cu izotretinoin poate induce acneea fulminans; în cazuri rare, poate fi indusă și de tetraciclină sau eritromicină (4)

- O altă ipoteză este că modificarea genetică a activității neutrofilelor - hiperreactivitatea la chemoatractanți - poate influența scăderea fagocitozei de P. acnes (5)
Sunt cazuri în care, prin administrarea dozelor mari de testosteron, a fost declanșată acneea fulminans - în unele cazuri, testosteronul a fost administrat concomitent cu steroizi anabolizanți (6-8). În unele cazuri, excesul de androgeni poate fi incriminat în declanșarea acneei fulminans.

Într-o altă ordine de idei, din cauza scăderii complementului C3 la unii pacienți, creșterea gama globulinelor și răspunsul bun la terapia cu steroizi conduc către perspectiva încadrării în bolile complexe autoimune.

La unele persoane, infecția poate să predispună declanșarea acneei fulminans.

Se mai presupun, ca factori declanșatori, factorii ereditari și cei genetici (predispoziția genetică se pare a fi asociată cu gena HLAcw6) (9).

Nivelul testosteronului crește în perioada pubertății, fiind corelat cu trendul de apariție a acneei fulminans cu precădere la sexul masculin în perioada de adolescență.

Un studiu de caz relatează cazul a doi frați, ambii în tratament cu izotretinoin. La unul dintre ei, izotretinoinul a indus pe parcursul unei acnee severe granuloame piogenice eruptive, iar la celălalt a dus la apariția acneei fulminans (10).

În ceea ce privește administrarea de izotretinoin ca posibilitate de declanșare a acneei fulminans, au fost relatate doze cuprinse între 40 $\mathrm{mg} / \mathrm{zi} \mathrm{și} 80 \mathrm{mg} / \mathrm{zi}$ pe o perioadă de la 1 săptămână până la 7 săptămâni (15).

\section{MANIFESTĂRI CLINICE}

Plecând de la ideea general acceptată, prin care majoritatea pacienților care dezvoltă acneea fulminans au deja o formă ușoară sau moderată de acnee, cel mai probabil tratată cu izotretinoin, ajungem la momentul debutului, care este brusc și exploziv.

Se prezintă ca o acnee foarte gravă ulcerativă având prezenți noduli inflamatori și hemoragici, acoperiți de cruste hemoragice, cel mai frecvent localizați pe față, umeri și partea superioară a trunchiului și spatelui $(11,12)$.

Drenarea este o variantă a unui nodul dermo-hipodermic ce fistulează, de obicei in forme severe de acnee, cum ar fi acneea fulminans, care este mai probabil să se dezvolte pe față și pe gât decât pe trunchi și se manifestă ca o leziune persistentă, care se extinde liniar și eliberează periodic puroi sau sânge (13).

Caracteristice acestei forme de acnee sunt manifestările sistemice care apar aproape în toate cazurile. 
Simptomele sistemice evidențiate la debutul bolii sunt: febră, frisoane, slăbiciune, artralgii, mialgii, oboseală, dureri musculo-scheletice, anemie, leucocitoză și creșterea ratei de sedimentare a eritrocitelor.

Cu o frecvență crescută, au fost raportate la acești pacienți artralgia, inflamația articulară și leziuni osoase osteolitice.

Afectarea osoasă este comună la acești pacienți, deși cauza este necunoscută, fiind utilizată biopsia osoasă pentru a exclude malignitatea sau infecția. Analiza probelor de biopsie a leziunilor osoase arată numai modificări reactive; cu toate acestea, un infiltrat de neutrofile și celule mononucleare cu țesut de granulare poate imita osteomielita (13).

În acneea fulminans putem să întâlnim: hepatosplenomegalie, eritem nodos sau miozită (14).

TABELUL 2. Caracteristici generale în acneea fulminans (15)

\begin{tabular}{|l|l|}
\hline Sex & Predominant masculin \\
\hline Vârstă & 13-22 ani \\
\hline Patogeneză & Incertă \\
\hline Debut & Acut și spontan \\
\hline Localizare & Trunchi, spate, umeri, față \\
\hline Clinic & $\begin{array}{l}\text { Leziuni ulcerative, acoperite cu cruste he- } \\
\text { moragice }\end{array}$ \\
\hline Sistemic & $\begin{array}{l}\text { Stare generală alterată, febră, oboseală, } \\
\text { scădere ponderală, artralgii și mialgii, le- } \\
\text { ziuni osoase osteolitice, splenomegalie, } \\
\text { hepatomegalie, indispoziție }\end{array}$ \\
\hline $\begin{array}{l}\text { Investigații } \\
\text { de laborator }\end{array}$ & $\begin{array}{l}\text { Leucocitoză, viteza de sedimentare a eri- } \\
\text { trocitelor crescută, anemie, proteinurie, } \\
\text { hematurie microscopică }\end{array}$ \\
\hline Tratament & $\begin{array}{l}\text { Corticosteroizi sistemici combinați cu izo- } \\
\text { tretinoin }\end{array}$ \\
\hline
\end{tabular}

Au fost descrise patru forme de acnee fulminans: 1 . Acnee fulminans cu simptomatologie sistemică; 2 . Acnee fulminans fără simptomatologie sistemică; 3 . Acnee fulminans indusă de izotretinoin, cu simptomatologie sistemică; 4. Acnee fulminans indusă de izotretinoin, fără simptomatologie sistemică (16).

\section{DIAGNOSTIC DIFERENTIIAL}

Este important să fie făcut diagnosticul diferențial între acneea fulminans și acneea conglobată. Deși au o localizare similară, acneea fulminans este mai distructivă, rezistentă la tratament cu antibiotice, limitată în timp și necesită o terapie aparte, în timp ce acneea conglobată apare la o vârstă mai înaintată, are un curs cronic și debut mai puțin exploziv (15).

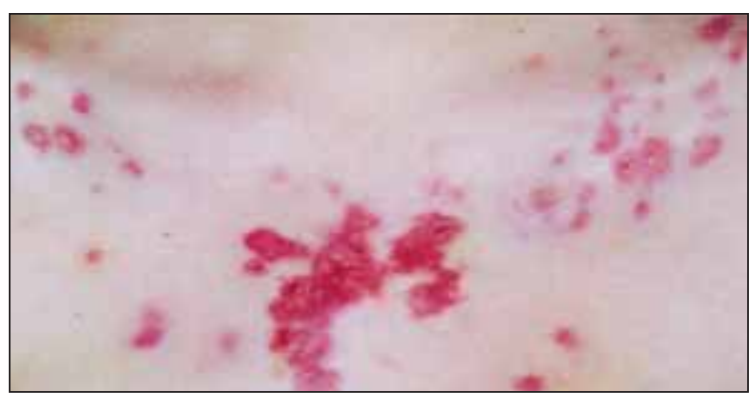

FIGURA 1. Acnee ulcerativă severă (acnee fulminans) extinsă ce afectează partea superioară a trunchiului (17)

\section{TRATAMENT}

De obicei, pacientul este internat pe o perioada de 3-5 săptămâni, necesitând repaus la pat. Pe lângă debridarea chirurgicală, se va utiliza local uree pentru a preveni formarea crustelor.

Tratamentul de elecție este reprezentat de steroizii sistemici. Răspunsul este bun la tratament, iar în cazul întreruperii prea rapide sau bruște a terapiei sunt frecvente recurențele, care apar la 2-8 săptămâni de la întrerupere. Durata optimă de tratament pentru a evita recăderile este de 3-5 luni.

Terapia orală cu izotretinoin este recomandată pentru tratamentul acneei severe, în ciuda unor posibile efecte adverse care trebuie luate în considerare la fiecare pacient în parte (18).

De asemenea, combinația de steroizi orali și izotretinoin aduce un beneficiu sporit pacientului, aceasta fiind considerată cea mai bună variantă terapeutică cu cel mai bun răspuns (19).

Mai nou, tratamentul cu infliximab poate fi considerat ca o variantă terapeutică pentru pacienții care nu răspund la terapiile convenționale (20).

Studiile au arătat că, în cazul imposibilității administrării steroizilor, dapsona poate fi o bună opțiune terapeutică (21).

În cazurile de acnee fulminans fără afectare sistemică, ar trebui luată în considerare schimbarea conduitei terapeutice, răspunsul la izotretinoin la acești pacienți fiind mic (22).

\section{DISCUTIII}

Prognosticul pentru pacienții tratați cu corticosteroizi și izotretinoin este bun.

Leziunile osoase se remit de obicei dacă tratamentul a fost efectuat corect, însă pot rămâne modificări radiologice reziduale, cum ar fi scleroza și hiperostoza.

Cicatricile și fibroza pot fi rezultatul procesului inflamator acut. 
Pot să apară recăderi, mai ales când tratamentul cu steroizi este redus, dar, după un tratament de 1 an, riscul de recădere este mic.

Acneea este un model interesant pentru studierea interacțiunilor dintre hormoni, imunitatea înnăscută, inflamație și cicatrizare, pentru a explora mecanismele de inducere a acneei în diferite boli/sindroame asociate cu acneea, pentru care sunt necesare studii suplimentare (23).

\section{CONCLUZII}

Recunoașterea promptă a acestei afecțiuni va ajuta la gestionarea adecvată a cazurilor. Diagnosticarea propice cu inițierea rapidă a terapiei adecvate, de lungă durată, permite pacienților să evite consultații multiple, tratamente farmacologice inutile, cicatrici reziduale și alte complicații. Apare necesitatea constituirii echipei multidisciplinare, cu identificarea atât a impactului negativ al acneei fulminans, cât și a tratamentului de lungă durată asupra calității vieții pacientului, și, nu în ultimul rând, elaborarea și aplicarea strategiilor pentru îmbunătățirea calității vieții acestor pacienți. Medicul de familie este primul aflat în contact cu pacientul, fiind important ca acesta să recunoască acneea fulminans pentru a direcționa pacientul cât mai rapid către medicul specialist.

Conflict of interest: none declared Financial support: none declared

\section{$\overline{\text { BIBLIOGRAFIE }}$}

1. Alakeel A., Ferneiny M., Auffret N., Bodemer C. Acne Fulminans: Case Series and Review of the Literature (2016). Pediatric Dermatology, 33: e388-e392. doi: 10.1111/pde.12983

2. Göksun Karaman, Ekin Savk, Meltem Uslu, Neslihan Sendur. Acne fulminans triggered by isotretinoin therapy, Journal of the American Academy of Dermatology, Volume 70, Issue 5, Supplement 1, 2014, Page AB5, ISSN 0190-9622.

3. Karvonen S.L., Rasanen L., Cunliffe W.J. et al. Delayed hypersensitivity to Propionibacterium acnes in patients with severe nodular acne and acne fulminans. Dermatology 1994; 189: 344-349.

4. Karvonen S.L. Acne fulminans: report of clinical findings and treatment of twentyfour patients. J Am Acad Dermatol 1993; 28: 572-579.

5. Perkins W., Crocket K.V., Hodgkins M.B. et al. The effect of treatment with 13-cis-retinoid acid on the metabolic burst of peripheral blood neutrophils from patients with acne. Br J Dermatol 1991; 124: 429-432.

6. Fyrand O., Fiskadaal H.J., Trygstad O. Acne in pubertal boys undergoing treatment with androgens. Acta Derm Venereol (Stockh) 1992; 72: 148-149.

7. Heydenreich G. Testosterone and anabolic steroids and acne fulminans. Arch Dermatol 1989; 125: 571-572.

8. Traupe H., von Muhlendahl K.E., Brämswig J. et al. Acne of the fulminans type following testosterone therapy in three excessively tall boys. Arch Dermatol 1988; 124: 414-417.

9. Darley C.R., Currey H.L., Baker H. Acne fulminans with arthritis in identical twins treated with isotretinoin. J R Soc Med 1984; 77: 328-330.

10. Blanc D., Zultak M., Wendling D. et al. Eruptive pyogenic granulomas and acne fulminans in two siblings treated with isotretinoin: a possible common pathogenesis. Dermatologica 1988; 177 : 16-18.

11. Dessinioti Andreas Katsambas. Difficult and rare forms of acne. Clinics in Dermatology, Volume 35, Issue 2, 2017, Pages 138-146, ISSN 0738-081X, https:// doi.org/10.1016/j.clindermatol.2016.10.005.

12. Mehrany K., Kist J.M., Weenig R.H. et al. Acne fulminans. Int J Dermatol 2005; 44: 132-133.

13. Jansen T., Romiti R., Plewig G., Altmeyer, P. Disfiguring Draining Sinus Tracts in a Female Acne Patient (2000). Pediatric Dermatology, 17: 123-125. doi:10.1046/j.1525-1470.2000.01728.x

14. Mélanie Saint-Jean, Cécile Frenard, Maëlle Le Bras, Guillaume Ghislain Aubin, Stéphane Corvec, Brigitte Dréno. Testosterone-induced acne fulminans in twins with Kallmann's syndrome, JAAD Case Reports, Volume 1, Issue 1, 2015, Pages 27-29, ISSN 2352-5126, https://doi. org/10.1016/j.jdcr.2014.10.005.

15. Zaba R., Schwartz R., Jarmuda S., Czarnecka-Operacz M., Silny W. Acne fulminans: explosive systemic form of acne (2011). Journal of the European Academy of Dermatology and Venereology, 25: 501-507. doi:10.1111/j.1468-3083.2010.03855.x

16. Greywal T., Zaenglein A.L., Baldwin H.E., Bhatia N., Chernoff K.A., Del Rosso J.Q., Eichenfield L.F., Levin M.H., Leyden J.J., Thiboutot D.M., Webster G.F., Friedlander S.F. Evidence-based recommendations for the management of acne fulminans and its variants, Journal of the American Academy of Dermatology, Volume 77, Issue 1, 2017, Pages 109-117, ISSN 0190-9622, https://doi.org/10.1016/j. jaad.2016.11.028.
17. Jansen T., Romiti R., Plewig G. Acute severe acne in a female patient (acne fulminans?) (1999). British Journal of Dermatology, 141: 945-947. doi:10.1046/j.1365-2133.1999.03187.x

18. Zouboulis C.C., Bettoli V. Management of severe acne (2015). Br J Dermatol, 172: 27-36. doi:10.1111/bjd.13639

19. Amir Hossein Siadat, Anis Bostakian, Bahareh Abtahi-Naeini, Masoom Shahbazi. Successful Treatment of Facial Acne Fulminans: Antimicrobial Agents and Oral Prednisolone as Promising Regimes. Case Reports in Dermatological Medicine, vol. 2017, Article ID 7092910, 3 pages, 2017. doi:10.1155/2017/7092910

20. Iqbal M., Kolodney M.S. Acne fulminans with synovitis-acne-pustulosis-hyperostosisosteitis (SAPHO) syndrome treated with infliximab. Journal of the American Academy of Dermatology, Volume 52, Issue 5, Supplement, 2005, Pages S118-S120, ISSN 0190-9622, https://doi.org/10.1016/j. jaad.2004.09.006.

21. Tan B.B., Lear J.T., Smith A.G. Acne fulminans and erythema nodosum during isotretinoin therapy responding to dapsone (1997). Clinical and Experimental Dermatology, 22: 26-27. doi:10.1046/j.1365-2230.1997.1830600.x

22. Thomson K.F., Cunliffe W.J. Acne fulminans 'sine fulminans' (2000). Clinical and Experimental Dermatology, 25: 299-301. doi:10.1046/j.1365-2230.2000.00647.x

23. Chen W., Obermayer-Pietsch B., Hong J.-B., Melnik B., Yamasaki O., Dessinioti C., Ju Q., Liakou A., Al-Khuzaei S., Katsambas A., Ring J., Zouboulis C. Acne-associated syndromes: models for better understanding of acne pathogenesis (2011). Journal of the European Academy of Dermatology and Venereology, 25: 637-646. doi:10.1111/j.1468-3083.2010.03937. 